\title{
Persisterende ductus arteriosus hos for tidlig fødte barn
}

\begin{abstract}
Sammendrag
Bakgrunn. Persisterende ductus arteriosus hos små premature blir ofte behandlet pga. en assosiasjon til forverret lungesykdom og komplikasjoner som bronkopulmonal dysplasi. Nyere forskningsresultater har endret synet på betydningen av persisterende ductus arteriosus.
\end{abstract}

Materiale og metode. Relevante publikasjoner er identifisert via oversiktsartikler i internasjonale fagvurderte tidsskrifter, hovedsakelig gjennom søk i PubMed og Cochrane-databasene.

Resultater. De senere års forskning har ført til et paradigmeskifte i synet på persisterende ductus arteriosus. Tilstanden, som tillater shunting av blod fra høyre til venstre når lungekarmotstanden er høy og som kan bedre lungegjennomblødningen ved shunting fra venstre til høyre hos barn med alvorlig lungesykdom, oppfattes nå delvis som fysiologisk hos premature. En persisterende ductus arteriosus forverrer ikke samtidig lungesykdom og disponerer ikke for bronkopulmonal dysplasi, hjerneblødning, nekrotiserende enterokolitt eller andre komplikasjoner til prematuritet.

Fortolkning. Profylaktisk eller tidlig lukning av persisterende ductus arteriosus med COX-hemmere som indometacin og ibuprofen synes å øke risikoen for bronkopulmonal dysplasi uten å redusere andre komplikasjoner eller dødelighet. En stor persisterende ductus arteriosus har sirkulatoriske konsekvenser og bør behandles. Væskerestriksjon, diuretika og ev. inotrope medikamenter bør prøves før det vurderes å lukke ductus. Kirurgisk lukning av persisterende ductus arteriosus hos små premature er assosiert med nevrosensoriske sekveler.

\section{Dag Bratlid}

dag.bratlid@ntnu.no

Barne- og ungdomsklinikken

St. Olavs hospital

Institutt for laboratoriemedisin,

barne- og kvinnesykdommer

Det medisinske fakultet

Norges teknisk-naturvitenskapelige universitet 7006 Trondheim

\section{Teresa Farstad}

Barne- og ungdomsklinikken

Akershus universitetssykehus

1478 Lørenskog

Ductus arteriosus forbinder i fosterlivet arteria pulmonalis med aorta. Etter fødselen skjer det en relativt rask sammentrekning av ductus, som er funksjonelt helt lukket i løpet av noen dager. Lukningen er resultatet av et samspill mellom flere faktorer, der økning av blodets oksygentensjon og reduksjon av konsentrasjonen av prostaglandinene PGE1, PGE2 og PGI1 etter fødselen er av vesentlig betydning (1). Hørbar bilyd over hjertet hos nyfødte de første dagene etter fødselen er ofte en ductus som ikke har lukket seg helt. Vanligvis oblitereres ductus arteriosus permanent i løpet av noen måneder, men kan være åpen i opptil et år.

Hos for tidlig fødte barn er det derimot vanlig at ductus arteriosus ikke lukker seg i løpet av de første levedagene, såkalt persisterende ductus arteriosus. Dette skyldes dels umodenhet i karveggens muskulatur, dels sykdommer som hindrer den normale stigningen i arteriell oksygentensjon etter fødselen. Forekomsten av persisterende ductus arteriosus er derfor inverst relatert til svangerskapets lengde ved fødselen og ses hyppigere hos barn med neonatalt åndenødssyndrom og andre tilstander som medfører problemer med oksygeneringen etter fødselen. Det er i tillegg angitt at fototerapi disponerer for utvikling av persisterende ductus arteriosus, og tilstanden har også vært satt i sammenheng med overvæsking av barnet de første levedagene (2). Persisterende ductus arteriosus forekommer hos ca. $50 \%$ av barn med fødselsvekt under $1000 \mathrm{~g}$.

I løpet av de 2-3 siste årene har det nærmest skjedd et paradigmeskifte i synet på persisterende ductus arteriosus hos premature barn. Fra å oppfatte tilstanden som en alvorlig komplikasjon til prematuritet som det var viktig å behandle også profylaktisk, mener mange eksperter nå at persisterende ductus arteriosus hos premature er en delvis fysiologisk tilstand som sjelden trenger behandling, bl.a. fordi behandlingen ser ut til å gi flere komplikasjoner enn selve tilstanden (3-6). Denne oversiktsartikkelen gir noe av bakgrunnen for dette synet.

\section{Materiale og metode}

Dette er en ikke-systematisk oversikt. Relevante publikasjoner er identifisert via oversiktsartikler i anerkjente internasjonale fagvurderte tidsskrifter, hovedsakelig gjennom søk i PubMed og Cochrane-databasene.

\section{Patofysiologisk betydning}

I fosterlivet shunter ductus fra høyre til venstre. Etter fødselen vil imidlertid en persisterende ductus arteriosus ha blodstrøm fra venstre til høyre (fra aorta til a. pulmonalis) fordi motstanden i aorta er høyere enn i a. pulmonalis. Hos helt nyfødte er imidlertid karmotstanden i lungene svært høy de første dagene etter fødselen, ofte på samme nivå som i systemsirkulasjonen (7). En bidireksjonal shunt er derfor ikke uvanlig de første levedagene, noe som kan medføre kortvarige fall $\mathrm{i}$ arteriell oksygenmetning ved uro og skrik og som øker lungekartrykket ytterligere. Først når motstanden i lungekretsløpet har sunket betraktelig, blir shunten fra venstre til høyre så stor at ductus får hemodynamisk betydning. Hos fullbårne barn kan dette ta noen uker.

\section{Symptomer hos premature}

Hos premature vil imidlertid de sirkulatoriske følgene av en persisterende ductus arteriosus kunne vises etter få dager. Det skyldes bl.a. at karmotstanden i lungekretsløpet faller raskere hos for tidlig fødte barn. I tillegg har premature dårligere utviklede kompensatoriske mekanismer, som bl.a. medfører at de ikke så lett kan øke slagvolum og hjertefrekvens for å opprettholde

\section{Hovedbudskap}

- Ductus påvirker ikke samtidig lungesykdom eller utviklingen av alvorlige komplikasjoner til prematuritet

- Profylaktisk eller tidlig lukning av ductus medfører sannsynligvis flere komplikasjoner enn selve tilstanden

- Kirurgisk lukning av ductus hos små premature er assosiert med nevrosensoriske sekveler 
et normalt systemisk minuttvolum. Dette synes å være ytterligere forverret hos barn som er alvorlig lungesyke (8). Utvikling av hjertesvikt med dilatasjon av venstre ventrikkel og atrium samt lungestuvning vil derfor vise seg tidligere hos premature enn hos fullbårne.

Persisterende ductus arteriosus har tidligere vært vurdert som en av de viktigste årsakene til en rekke senfølger hos for tidlig fødte barn. Dersom barnet ikke klarer å øke hjertets minuttvolum for å kompensere for det blodet som shuntes over ductus, vil man kunne se reversering av den diastoliske blodstrømmen i aorta (ductal steal). Dette vil kunne føre til redusert blodstrøm til andre organer, særlig hjerne, nyre og tarm $(9,10)$. Persisterende ductus arteriosus har derfor vært koplet til hjerneskade (både blødning og periventrikulær leukodystrofi) med utvikling av cerebral parese, nekrotiserende enterokolitt og økt mortalitet. Det har i særlig grad også vært hevdet at en hemodynamisk signifikant ductus vil forlenge respiratorbehovet, med økt risiko for bronkopulmonal dysplasi.

Det er vanskelig å vurdere den hemodynamiske betydningen av en persisterende ductus arteriosus bare ut fra kliniske variabler som bilydens karakter, pulstrykk, blodtrykk og graden av hyperaktivt prekordium. Indikasjon for behandling vil derfor i de fleste tilfeller bedømmes ut fra en samlet vurdering av kliniske, radiologiske og ekkokardiografiske variabler (11).

\section{Påvirkning på lungefunksjon}

En hemodynamisk betydningsfull ductus arteriosus hos et lungesykt prematurt barn assosieres ofte med forverring av det kliniske bildet, uttrykt gjennom økt oksygenbehov og respiratorstøtte. Det er imidlertid vist at påvirkningen på barnet i mindre grad er relatert til shuntens størrelse, men bestemmes av om barnet klarer å kompensere for shunten ved å øke hjertets minuttvolum, slik at systemsirkulasjonen opprettholdes (8). Den kliniske tilstanden hos et sykt barn kan derfor bli betydelig forverret av en relativt liten shunt, samtidig som en stor shunt ikke behøver å påvirke et friskere barn på andre måter enn at hjertet må arbeide kraftigere.

Disse funnene støttes også av en omfattende dyrestudie (10). Ved å preparere ductus med formalin kunne man etablere en permanent persisterende ductus arteriosus hos nyfødte lam og variere blodstrømmen til lungene ved å manipulere størrelsen på ductus. Man fant overraskende nok at den økte blodstrømmen til lungene ved hhv. en liten, en moderat og en stor shunt ikke hadde noen påvirkning på lungenes elastisitet eller motstand.

Det er imidlertid publisert få kliniske studier over lungemekaniske effekter av en persisterende ductus arteriosus hos premature, og de fleste studier er gjort i forbindelse med lukning av ductus (12-15). De fleste finner ingen eller liten endring av de lungemekaniske variabler etter at ductus er lukket. Det er derfor trolig at klinisk forverring av lungesykdom som følge av persisterende ductus arteriosus skyldes effekter på systemsirkulasjonen snarere enn effekter på lungene. Man kan imidlertid ikke se bort fra at en persisterende ductus arteriosus også kan ha en negativ påvirkning på gassutvekslingen uten at dette fanges opp av lungemekaniske tester, f.eks. gjennom påvirkning av diffusjonsprosessene.

\section{Påvirkning på hjertefunksjon og sirkulasjon}

Det er derimot ingen tvil om at en persisterende ductus arteriosus påvirker systemsirkulasjonen. Dyrestudier har vist økende systolisk og avtakende diastolisk trykk samt økt slagvolum og minuttvolum når blodstrømmen i shunten øker (10), slik man også finner ved ekkokardiografi hos premature (8). Ved riktig store shunter vil den diastoliske blodstrømmen i aorta kunne bli svært lav og også reverseres når økningen i minuttvolumet ikke lenger klarer å kompensere for shunten. Måling av hjertets minuttvolum vil derfor være nyttig hos premature. Dette er imidlertid praktisk vanskelig hos syke nyfødte ved rutinemessig ekkokardiografisk måling av blodstrømmen på aortaklaffenivå eller ascenderende/descenderende aorta (8). Måling av hjertets minuttvolum inngår derfor vanligvis ikke $\mathrm{i}$ vurderingen av den hemodynamiske betydningen av en persisterende ductus arteriosus. Det er imidlertid vist at måling av blodstrøm i øvre hulvene er et godt substitutt for hjertets minuttvolum og betydelig enklere å måle $(16,17)$. Slik diagnostikk bør antakelig få en større plass i vurderingen av en persisterende ductus arteriosus.

\section{Behandling av premature}

Det har hittil vært sett på som viktig at en persisterende ductus arteriosus blir behandlet så raskt og effektivt som mulig når den oppstår. Mange har også anbefalt profylaktisk behandling til de aller minste og sykeste barna (18). Behandlingen er enten kirurgisk lukning med klips eller sutur gjennom en venstresidig torakotomi eller medikamentell lukning ved hjelp av COX-hemmere som in-

Tabell 1 Persisterende ductus arteriosus (PDA) hos premature barn med svangerskapslengde 22-30 uker. Mortalitet og bronkopulmonal dysplasi er angitt i henhold til forekomst av persisterende ductus arteriosus (ikke eller asymptomatisk) og den behandling barn med symptomgivende persisterende ductus arteriosus ble gitt (bare indometacin, bare kirurgi, indometacin og påfølgende kirurgi, eller bare væskerestriksjon). Barn som døde i løpet av de første to døgn (før tilstanden vanligvis blir symptomatisk) og barn som ikke ble behandlet med respirator ved 24 timers alder, er ikke inkludert. Grunnlagsdata er hentet fra databasen i Prosjekt Ekstrem Prematuritet (23)

\begin{tabular}{|c|c|c|c|c|c|}
\hline & $\begin{array}{l}\text { Svangerskaps- } \\
\text { lengde }\end{array}$ & Antall & $\mathrm{Død}(\%)$ & $\begin{array}{l}\text { Bronkopulmonal } \\
\text { dysplasi }(\%)\end{array}$ & $\begin{array}{l}\text { Død/bronkopulmonal } \\
\text { dysplasi }(\%)\end{array}$ \\
\hline Hele kohorten & $22-30$ & 272 & $36(13,2)$ & $130(47,8)$ & $158(58,1)$ \\
\hline \multicolumn{6}{|l|}{ Behandlet for persisterende ductus arteriosus } \\
\hline Bare indometacin & $24-29$ & 24 & & & \\
\hline Bare kirurgi & $22-27$ & 30 & & & \\
\hline Indometacin og kirurgi & $23-27$ & 10 & & & \\
\hline Totalt & & 64 & $5(7,8)$ & $44(68,8)^{1}$ & $46(71,9)^{1,2}$ \\
\hline Bare væskerestriksjon & $23-29$ & 18 & $4(22,2)$ & $10(55,6)$ & $12(66,7)$ \\
\hline $\begin{array}{l}\text { Ikke behandlet for persisterende ductus } \\
\text { arteriosus }^{3}\end{array}$ & $22-30$ & 178 & $26(14,6)$ & $72(40,4)$ & $96(53,9)$ \\
\hline $\begin{array}{l}\text { Asymptomatisk persisterende ductus } \\
\text { arteriosus }\end{array}$ & $24-28$ & 37 & $5(13,5)$ & $12(32,4)$ & $17(45,9)$ \\
\hline $\begin{array}{l}\text { Ikke holdepunkter for persisterende ductus } \\
\text { arteriosus }\end{array}$ & $22-30$ & 141 & $21(14,9)$ & $60(42,6)$ & $79(56,0)$ \\
\hline
\end{tabular}


dometacin eller ibuprofen (19). Detaljene i denne behandlingen vil ikke bli omtalt nærmere her, men i metaanalyser er det ikke vist signifikante forskjeller i behandlingsresultatene mellom ibuprofen eller indometacin (20), mellom lang eller kort behandlingskur (21) og heller ikke mellom kirurgisk eller medikamentell lukning (19). Det synes heller ikke å være vesentlige forskjeller i de umiddelbare bivirkningene av behandlingen, bortsett fra at kirurgisk lukning sjelden påvirker nyrefunksjonen, slik man kan se ved behandling med COX-hemmere og da særlig indometacin.

Det er få studier der man redegjør for forløpet av en ubehandlet persisterende ductus arteriosus hos premature. I en studie fra 1978 fulgte man premature med fødselsvekt $\leq 1500 \mathrm{~g} \mathrm{og}$ neonatalt åndenødssyndrom som utviklet hjertesvikt pga. persisterende ductus arteriosus (22). Disse barna fikk medikamentell hjertesviktbehandling, og ductus lukket seg til slutt hos de aller fleste. Barn med persisterende ductus arteriosus hadde signifikant lengre tid på respirator enn barn uten persisterende ductus arteriosus og også noe høyere mortalitet enn barn uten persisterende ductus arteriosus, men denne forskjellen var ikke signifikant.

Tabell 1 viser forekomsten av behandlingstrengende persisterende ductus arteriosus $i$ en kohort av små premature fra den norske prematuritetsstudien (23) (tab 1). Dødelighet og forekomst av bronkopulmonal dysplasi er vist i relasjon til ulike behandlingsstrategier. Som det fremgår, var kirurgisk lukning det vanligste hos de aller minste. Av 17 behandlede barn med gestasjonsalder $\leq 24$ uker ble ductus lukket kirurgisk hos 15 .

\section{Nyere synspunkter}

Allerede i de første studiene av tidlig behandling av persisterende ductus arteriosus hos små premature hadde man problemer med å vise en sammenheng mellom persisterende ductus arteriosus og mortalitet eller morbiditet. Selv profylaktisk kirurgisk lukning av ductus første levedøgn hos premature med fødselsvekt $\leq 1000 \mathrm{~g}$ viste ingen forskjell i mortalitet, bronkopulmonal dysplasi, prematuritetsretinopati eller hjerneblødning sammenliknet med barn som først fikk lukket sin ductus når en hemodynamisk signifikant ductus ble diagnostisert senere i sykdomsforløpet (24). Heller ikke i en studie der premature med fødselsvekt $\leq 1300 \mathrm{~g}$ ble randomisert til behandling med indometacin eller placebo fra 12 timers alder, fant man noen sikker forskjell i varighet av oksygenbehandling eller respiratorbehandling, heller ingen forskjell i bronkopulmonal dysplasi, sepsis, nekrotiserende enterokolitt, prematuritetsretinopati eller mortalitet, selv om barn som fikk indometacin hadde signifikant lavere forekomst av persisterende ductus arteriosus (25). Behandlede barn hadde imidlertid mindre forekomst av alvor- lig hjerneblødning. Det er senere vist at dette skyldes en direkte virkning av indometacin på cerebrale kar uavhengig av lukning av ductus (26).

Det er særlig resultatene fra den store TIPP-studien (Trial of Indomethacin Prophylaxis in Preterm Infants) som nå nærmest har ført til et paradigmeskifte i synet på betydningen av en persisterende ductus arteriosus (27-29). Mange hevder nå at denne tilstanden har en beskjeden patofysiologisk betydning hos for tidlig fødte barn. Den skal derfor sannsynligvis bare behandles hos et fåtall barn (3-6). Det pekes bl.a. på at persisterende ductus arteriosus er en fysiologisk tilstand som hos premature tillater shunting av blod mellom de to kretsløpene, fra høyre til venstre de første levedøgnene når lungekarmotstanden er høy, og fra venstre til høyre dersom det tilkommer alvorlig lungesykdom som vil tjene på en bedret lungegjennomblødning. I to lederartikler i The Journal of Pediatrics er det pekt på at konsekvensene av behandlingen (bivirkninger av medikamenter og negative effekter av et kirurgisk inngrep) kanskje er verre enn konsekvensene av selve tilstanden $(5,6)$. I det følgende vil vi derfor spesielt gjennomgå de rapportene som ligger bak dette paradigmeskiftet.

I den første rapporten fra TIPP-studien fant man at profylaktisk behandling av en persisterende ductus arteriosus ikke hadde noen effekt på overlevelse eller nevrosensorisk funksjon vurdert ved 18 måneders alder, selv om forekomsten av signifikant persisterende ductus arteriosus ble mer enn halvert hos de barna som fikk profylaktisk behandling med indometacin i forhold til dem som ble gitt placebo ( $24 \%$ versus $50 \%$ ) (27). I den neste rapporten fant man heller ingen forskjell i forekomsten av bronkopulmonal dysplasi mellom de to gruppene (28). Imidlertid, mens forekomsten av bronkopulmonal dysplasi var $30 \%$ hos dem med persisterende ductus arteriosus som hadde fått placebo, var den signifikant høyere (43\%) hos dem som hadde fått indometacin og likevel utviklet en persisterende ductus arteriosus. Dette antas å skyldes at indometacin som en COX-inhibitor hemmer nyrefunksjonen og kan føre til væskeretensjon. Det har tidligere vært vist at premature med et relativt stort postnatalt vekttap, et vekttap som hovedsakelig skyldes reduksjon av det ekstracellulære væskerom (ECV) (2), har mindre risiko for utvikling av bronkopulmonal dysplasi enn barn som ikke kvitter seg med like mye ekstracellulærvæske. Man antar derfor at økningen i bronkopulmonal dysplasi etter behandling med indometacin skyldes økt ekstracellulærvæske i lungene med behov for økt respiratortrykk og oksygen. I den siste rapporten fant man at kirurgisk lukning av ductus medførte en nesten signifikant reduksjon i mortalitet, men samtidig en signifikant større risiko for nevrosensorisk utviklingshemning ved 18 måneders alder, i tillegg til økt forekomst av prematuritetsreti- nopati og bronkopulmonal dysplasi (29). Disse resultatene understøttes også av andre (30). En tidligere studie har dessuten vist en generell sammenheng mellom kirurgi i neonatalperioden og nevrosensoriske avvik ved fem års alder (31), noe som tyder på at kirurgi (og anestesi) kan være en isolert risikofaktor hos svært små premature.

\section{Konklusjon}

Det synes å foreligge overbevisende data på at det ikke er noen indikasjon for profylaktisk eller tidlig behandling av en persisterende ductus arteriosus hos et lite prematurt barn, selv om det foreligger alvorlig lungesykdom med respiratorbehov. Det er ikke holdepunker for at en hemodynamisk signifikant persisterende ductus arteriosus er av betydning for det totale sykdomsforløpet eller senere komplikasjoner. Den påvirker ikke barnets lungefunksjon, øker ikke risikoen for utviklingen av bronkopulmonal dysplasi og vil hos de aller fleste lukkes spontant uten spesifikk behandling. Barn som utvikler hjertesvikt bør derfor primært behandles med væskerestriksjon, ev. også med diuretika og inotrope medikamenter. Kirurgisk behandling av en persisterende ductus arteriosus bør i størst mulig grad unngås.

Paradigmeskiftet har ført til økt erkjennelse av at vi mangler kunnskapsbasert viten om indikasjonen for å lukke ductus også i de tilfellene der det foreligger betydelig sirkulatorisk påvirkning med sviktende minuttvolum og sterkt redusert eller reversert diastolisk blodstrøm i aorta (3-5). Den siste rapporten fra TIPP-studien kan tyde på at kirurgisk lukning kan være gunstig med tanke på overlevelse hos slike spesielle kasus (28), selv om det også synes å øke risikoen for nevrosensoriske avvik. Som påpekt bør dette undersøkes $i$ en randomisert studie av lukning av ductus mot placebo (5). Selv om mange vil mene at en slik studie vil være uetisk på bakgrunn av den lange tradisjon man har for aktiv behandling av en hemodynamisk signifikant ductus arteriosus, er det antakelig like uetisk ikke å gjennomføre en slik studie (5). Etter vår oppfatning vil bestemmelse av hjertets minuttvolum være en helt sentral variabel i en slik studie.

\section{Oppgitte interessekonflikter: Ingen}

\footnotetext{
Litteratur

1. Clyman RI. Mechanisms regulating the ductus arteriosus. Biol Neonate 2006; 89: $330-5$

2. Oh W, Poindexter BB, Perritt R et al. Association between fluid intake and weight loss during the first ten days of life and risk of bronchopulmonary dysplasia in extremely low birth weight infants. J Pediatr 2005; 147: 786-90.

3. Laughon MM, Simmons MA, Bose CL. Patency of the ductus arteriosus in the premature infant: reated? Curr Opin Pediatr 2004; 16: 146-51

4. Bose BL, Laughon MM. Patent ductus arteriosus: lack of evidence for common treatments. Arch Dis Child Fetal Neonatal Ed 2007: 92: F498-502.
} 
5. Bose $\mathrm{CL}$, Laughon ML. Treatment to prevent patency of the ductus arteriosus: Beneficial or harmful? J Pediatr 2006; 148: 713-4.

6. Clyman RI, Chome N. Patent ductus arteriosus: evidence for and against treatment. J Pediatr 2007; 150: 216-9.

7. Spitzer AR, Davis J, Clarke WT et al. Pulmonary hypertension and persistent fetal circulation in the newborn. Clin Perinatol 1988; 15: 389-413.

8. Mellander M, Larsson LE. Effects of left-to-right ductus shunting on left ventricular output and cerebral blood flow velocity in 3-day-old preterm infants with and without severe lung disease. J Pediatr 1988; 113: 101-9.

9. Perlman JM, Hill A, Volpe JJ. The effect of patent ductus arteriosus on flow velocity in the anterior cerebral arteries: ductal steal in the premature newborn infant. J Pediatr 1981; 99: 767-71.

10. Clyman RI, Mauray F, Heymann MA et al. Cardiovascular effects of patent ductus arteriosus in preterm lambs with respiratory distress. J Pediatr 1987; 111: 579-87

11. Skelton R, Evans N, Smythe J. A blinded comparison of clinical and echocardiographic evaluation of the preterm infant for patent ductus arteriosus. J Paediatr Child Health 1994; 30: 406-11.

12. Gerhardt T, Bancalari E. Lung compliance in newborns with patent ductus arteriosus before and after surgical ligation. Biol Neonate 1980; 38: 96-105.

13. Heldt GP, Pesonen ET, Merrit TA et al. Closure of the ductus arteriosus and mechanics of breathing in preterm infants after surfactant replacement therapy. Pediatr Res 1989; 25: 305-21.

14. Stefano JL, Abbasi S, Pearlman SA et al. Closure of the ductus arteriosus with indomethacin in ventilated neonates with respiratory distress syndrome. Am Rev Respir Dis 1991: 143: 236 -9.

15. Farstad T, Bratlid D. Pulmonary effects of closure of patent ductus arteriosus in premature infants with severe respiratory distress syndrome. Eur J Pediatr 1994; 153: 903-5.
16. Kluckow M, Evans N. Superior vena cava flow in newborn infants: a novel marker of systemic blood flow. Arch Dis Child Fetal Neonatal Ed 2000; 82 F182-7.

17. Osborn DA, Evans N, Kluckow M. Effect of early targeted indomethacin on the ductus arteriosus and blood flow to the upper body and brain in the preterm infant. Arch Dis Child Fetal Neonatal Ed 2003; 88: F477-82.

18. Cooke L, Steer P. Woodgate P. Indomethacin for asymptomatic patent ductus arteriosus in preterm infants. Cochrane Database Syst Rev 2003; nr. 2: CD003745.

19. Malviya M, Ohlsson A, Shah S. Surgical versus medical treatment with cyclooxygenase inhibitors for symptomatic patent ductus arteriosus in preterm infants. Cochrane Database Syst Rev 2003; nr. 3: CD003951.

20. Ohlsson A, Wakia R, Shah S. Ibuprofen for the treatment of patent ductus arteriousus in preterm and/or low birth weight infants. Cochrane Database Syst Rev 2005; nr. 4: CD003481.

21. Herrera C, Holberton J, Davis P. Prolonged versus short course of indomethacin for the treatment of patent ductus arteriosus in preterm infants. Coch rane Syst Rev 2007; nr. 2: CD003480

22. Cotton RB, Stahlman MT, Kovar I et al. Medical management of small preterm infants with symptomatic patent ductus arteriosus. J Pediatr 1978 92: $467-73$

23. Markestad T, Kaaresen PI, Rønnestad A et al. Early death, morbidity and need of treatment among extremely premature infants. Pediatrics 2005; 115 1289-98

24. Cassady G, Crouse DT, Kiklin JW et al. A randomized controlled trial of very early prophylactic ligation of the ductus arteriosus in babies who weighed $1000 \mathrm{~g}$ or less at birth. N Engl J Med 1989; 320: $1511-6$.

25. Bandstra ES, Montalvo BM, Goldberg et al. Prohylactic indomethacin for prevention of intraventri- cular hemorrhage in premature infants. Pediatrics 1988; 82: 533-42

26. van Bel F, Van de Bor M, Stijnen T et al. Cerebral blood flow velocity changes in preterm infants after a single dose of indomethacin: duration of its effect. Pediatrics 1989; 84: 802-7.

27. Schmidt B, Davis P, Moddemann D et al. Longterm effects of indomethacin prophylaxis in extremely-low-birth-weight infants. N Engl J Med 2001: 344: 1966-72

28. Schmidt B, Roberts RS, Fanaroff A et al. Indomethacin prophylaxis, patent ductus arteriosus and the risk of bronchopulmonary dysplasia: Further analyses from the trial of indomethacin prophylaxis in preterms (TIPP). J Pediatr 2006; 148: $730-4$

29. Kabra NS, Schmidt B, Roberts RS et al. Neurosensory impairment after surgical closure of patent ductus arteriosus in extremely low birth weight infants. Results from the Trial of Indomethacin Prophylaxis in Preterms. J Pediatr 2007; 150: $229-34$

30. Chorne N, Leonard C, Piecuch R et al. Patent ductus arteriosus and its treatment as risk factors for neonatal and neurodevelopmental morbidity. Pediatrics 2007; 119: 165-74.

31. Victorian Infant Collaborative Study Group. Surgery and the tiny baby: sensorineural outcome at 5 years of age. J Paediatr Child Health 1996; 32: 167-72.

Manuskriptet ble mottatt 21.11.2007 og godkjent 16.4.2009. Medisinsk redaktør Erlend Hem.

Denne artikkelen er blitt forsinket. Det skyldes ikke forfatterne. 